\title{
Sifat Fisis dan Akustik Komposit Serat Daun Lidah Mertua dengan Serbuk Gergaji sebagai Peredam Bunyi
}

\author{
Arifin Nur Muhammad Haryadi, Yazid Zainur Isnen, Nur Khusaenah, Kamila Fatma Adira, Hanifatus \\ Sa'adah, Ana Muawanah, Kartika Sari"
}

Jurusan Fisika, FMIPA Universitas Jenderal Soedirman

J1. Dr. Soeparno 61, Karangwangkal, Purwokerto 53122

*E-mail: kartika.sari@unsoed.ac.id

Diterima: 08-10-2021; Direvisi: 22-10-2021; Dipublikasi: 30-12-2021

\begin{abstract}
Abstrak
Material berbahan dasar alam (biomaterial) menjadi alternatif pengganti serat sintetis yang sedang dikembangkan saat ini. Penggunaan serat biomaterial karena memiliki keunggulan yaitu kekuatan dan ketangguhan tinggi, relatif murah dan mudah didapatkan. Penelitian ini bertujuan untuk memanfaatkan biomaterial sebagai peredam bunyi. Bahan dasar alam yang digunakan dalam penelitian adalah serat daun lidah mertua dengan serbuk gergaji. Adapun perbandingan konsentrasi fraksi volume dari serat daun lidah mertua, serbuk gergaji, dan epoksi resin sebesar 20\%:30\%:50\%, 25\%:25\%:50\%, dan 30\%:20\%:50\%. Variasi ketebalan yang digunakan sebesar $2 \mathrm{~cm}$ untuk koefisien serap bunyi dan $0,5 \mathrm{~cm}$ untuk uji pecah. Pengujian yang dilakukan untuk menentukan nilai koefisien serap bunyi menggunakan metode tabung impedansi pada frekuensi $250-3000 \mathrm{~Hz}$ dan pengujian pecah dilakukan dengan metode Charpy. Hasil pengujian koefisien serap bunyi yang optimum dengan konsentrasi 30\%:20\%:50\% sebesar 0,877. Sedangkan, hasil pengujian impak yang optimum dengan konsentrasi 20\%:30\%:50\% sebesar 3,262 $\mathrm{J} / \mathrm{mm}^{2}$. Hasil penelitian menunjukkan hubungan antara koefisien serap bunyi dengan uji impak adalah semakin banyak konsentrasi serat daun lidah mertua yang digunakan maka nilai koefisien serap bunyi semakin tinggi karena pori-pori terbentuk semakin banyak di komposit, namun nilai uji impaknya akan menurun. Kesimpulannya bahwa serat daun lidah mertua dan serbuk gergaji dapat digunakan sebagai biomaterial penyerap bunyi.
\end{abstract}

Kata kunci: Serat daun lidah mertua; serbuk gergaji; uji koefisien serap bunyi; uji kuat pecah

\begin{abstract}
Natural-based materials (biomaterials) are an alternative to synthetic fibers that are currently being developed. The use of biomaterial fibers because it has the advantage of high strength and toughness, cheaper and easy to obtain. This study aims to utilize biomaterials as sound absorbers. The natural base material used in the study was fiber from the leaf of the Sansevieria Trifasciata with sawdust. The ratio of the volume fraction concentration of Sansevieria Trifasiata leaf fiber, sawdust, and epoxy resin was 20\%:30\%:50\%, 25\%:25\%:50\%, and 30\%:20\%:50\%. The thickness used for the sound absorption coefficient is $2 \mathrm{~cm}$ and for the impact test is $0.5 \mathrm{~cm}$. The sound absorption coefficient test was carried out using the impedance tube method at a frequency ranges of 250-3000 Hz and the impact test was carried out using the Charpy method. The optimum result of the sound absorption coefficient for the sample 30\%:20\%:50\% which is 0.877. The optimum impact test result for sample 20\%:30\%:50\% is $3.262 \mathrm{~J} / \mathrm{mm}^{2}$. The results showed that the correlation between the sound absorption coefficient and the impact test was that the more fiber concentration of Sansevieria Trifasicata leaf was used, the higher the sound absorption coefficient value because of the large number of pores formed in the composite, but the impact test value would decrease. The conclusion is that Sansevieria Trifasciata leaf fiber and sawdust can be used as sound-absorbing biomaterials.
\end{abstract}

Keywords: Impact strength test; Sansevieria Trifasciata leaf fiber; Sawdust; Sound absorber coefficient test

\section{Pendahuluan}

Polusi atau limbah dapat berasal dari hasil kegiatan manusia berupa suara. Kebisingan adalah salah satu polusi yang dihasilkan dari aktivitas manusia[1]. Bunyi yang berasal dari kendaraan atau industri dapat menimbulkan masalah kebisingan sehingga mengganggu dan menurunkan kemampuan pendengaran manusia. Peredam bunyi merupakan salah satu usaha untuk mengurangi kebisingan. Komposit dapat dijadikan sebagai bahan peredam bunyi karena mengandung 
filler sebagai penguat dan matriks sebagai pengikat. Serat daun lidah mertua dan serbuk gergaji merupakan alternatif yang digunakan sebagai bahan peredam bunyi pada penelitian ini. Indonesia merupakan salah satu negara di dunia yang memiliki kekayaan alam berupa serat alam atau serat nabati yang sangat berlimpah dan belum banyak dimanfaatkan secara optimal. Jenis serat ini dapat dimanfaatkan sebagai bahan pengisi (filler) pada bahan komposit. Bahan komposit secara umum terdiri dari dua unsur, yaitu serat (fiber) sebagai bahan penguat dan bahan pengikat seratserat tersebut yang disebut matriks. Komposit juga dapat dibentuk dari kombinasi dua atau lebih material, baik logam, organik, maupun anorganik [2].

Pengisi (filler) komposit biasanya adalah bahan yang memiliki sifat tertentu dari produk akhir komposit bertujuan untuk menambah sifat yang dimiliki oleh matriks seperti kekuatan mekanik, akustik, listrik dan magnetik. Bahan pengisi dapat berasal dari produk alam maupun sintetis, masing-masing bahan memiliki keuntungannya jika digunakan sebagai pengisi [4]. Bahan alami sebagai penguat memiliki keuntungan antara lain mudah didapatkan, bahan tersebut biasanya murah karena berbentuk limbah, tidak memerlukan proses mendalam dalam pengolahannya dan dapat terurai secara alami di alam. Bahan-bahan seperti serat alam, limbah industri kayu seperti serbuk gergaji, dan limbah pertanian biasanya digunakan sebagai pengisi komposit untuk menghasilkan sifat-sifat tertentu.

Uji kuat pecah dilakukan untuk menguji ketangguhan suatu komposit bila diberikan beban secara tiba-tiba melalui tumbukan. Pengujian kuat pecah berfungsi untuk mengetahui sifat fisis material dan keuletan komposit yang telah dibuat. Prinsip pengujian pecah adalah menghitung energi yang diberikan dari beban dan energi yang diserap oleh sampel. Energi kinetik maksimum terjadi ketika beban memiliki energi potensial yaitu saat beban dinaikkan pada ketinggian tertentu. Pengujian pecah terdapat dua metode yaitu Charpy dan Izod. Perbedaannya adalah terletak pada posisi spesimen yang akan diuji dimana uji pecah Charpy posisi spesimen horizontal sedangkan uji pecah Izod posisi spesimen vertikal [6]. Penelitian tentang komposit berbahan dasar serat daun lidah mertua dengan komposisi fraksi volume $40 \%$ matriks dan $60 \%$ filler menghasilkan kuat pecah sebesar $0,252 \mathrm{~J} / \mathrm{mm}^{2}$ [7]. Kuat pecah bahan dasar kertas sebesar $9,51 \times 10^{-3} \mathrm{~J} / \mathrm{mm}^{2}[8]$.

Gelombang bunyi datang mengenai permukaan batas material maka gelombang bunyi akan ada yang dipantulkan, ditransmisikan, dan diserap [5]. Energi yang terserap ketika gelombang bunyi datang disebut dengan koefisien serap bunyi. Gelombang bunyi yang diserap oleh material mengakibatkan berkurangnya intensitas gelombang bunyi. Taraf intensitas bunyi terjadi karena rentang intensitas yang dapat ditangkap oleh telinga cukup luas dan gangguan rangsangan psikologis kenyaringan tidak berubah secara langsung tapi lebih mendekati logaritmik. Material penyerap bunyi baik adalah material dengan transmisi bunyi yang efisien. Material konstruksi penyerap bunyi dapat dipasang pada dinding ruangan atau digantung di udara. Penggunaan serat daut lidah mertua dan polystryrene variasi ketebalan 3 $\mathrm{cm}$ sebagai peredam bunyi menghasilkan koefisien serap bunyi sebesar 0,45 [8]. Penelitian tentang koefisien serap bunyi berbahan dasar serabut kelapa, pelepah pisah, daun lidah mertua dan epoksi resin menghasilkan koefisien serap bunyi sebesar 0,4 dengan frekuensi $6500 \mathrm{~Hz}$ [8].

Peredam bunyi yang telah diuji dapat diaplikasikan menjadi panel akustik pada ruang bangunan. Penggunaan serat sintetis tidak ramah lingkungan menimbulkan masalah limbah menumpuk dan sulit terurai. Serat alami dapat dijadikan alternatif pengganti serat sintetis karena memiliki keunggulan dapat terdegradasi di alam (biodegradasi), kekuatan dan ketangguhan tinggi, sifat termal baik, relatif murah, dan mudah didapatkan. Pemanfaatan serat daun lidah mertua dan serbuk gergaji masih kurang digunakan sehingga menjadi limbah yang tidak berguna [9]. Komposit diuji menggunakan metode tabung impedansi untuk menentukan koefisien serap bunyi yang sesuai dengan ISO 1165 dan uji mekanik untuk menentukan kuat pecahnya sesuai dengan standard ASTM E23. Komposit yang memiliki kuat pecah rendah 
menunjukkan penyerap bunyi yang baik pada masa sekarang. Beberapa komposit berpori dan berlapis digunakan sebagai peredam bunyi dan isolator.

\section{Material dan metodologi}

\subsection{Material dan Metode}

Alat yang digunakan dalam penelitian pembuatan dan pengujian komposit peredam bunyi adalah neraca digital, mesin press hidrolik, alat uji koefisien absorbsi bunyi metode tabung impedansi, dan alat uji pecah. Sedangkan, bahan yang digunakan adalah serat daun lidah mertua, serbuk gergaji, epoksi resin dan epoksi hardener. Pembuatan dan pengujian komposit peredam bunyi dilakukan di Laboratorium Fisika Inti Material UNSOED, Laboratorium Inti Atom (Akustik) UGM, dan Laboratorium Bahan Teknik UGM.

\subsection{Desain Penelitian}

Desain penelitian yang dilakukan ditunjukkan Gambar 1.

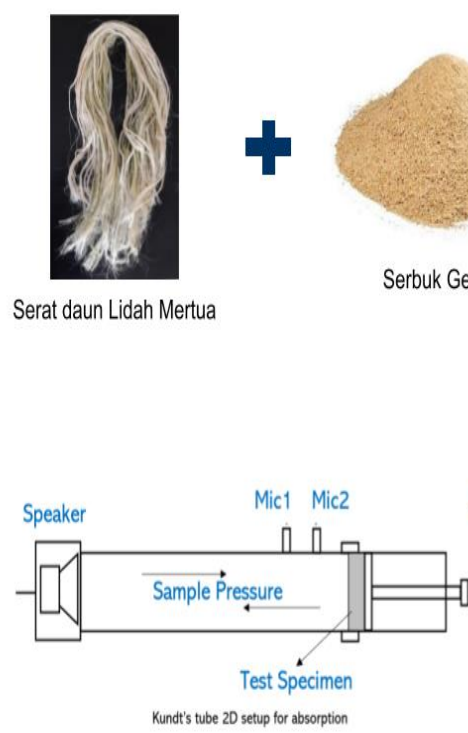

Uji Impak
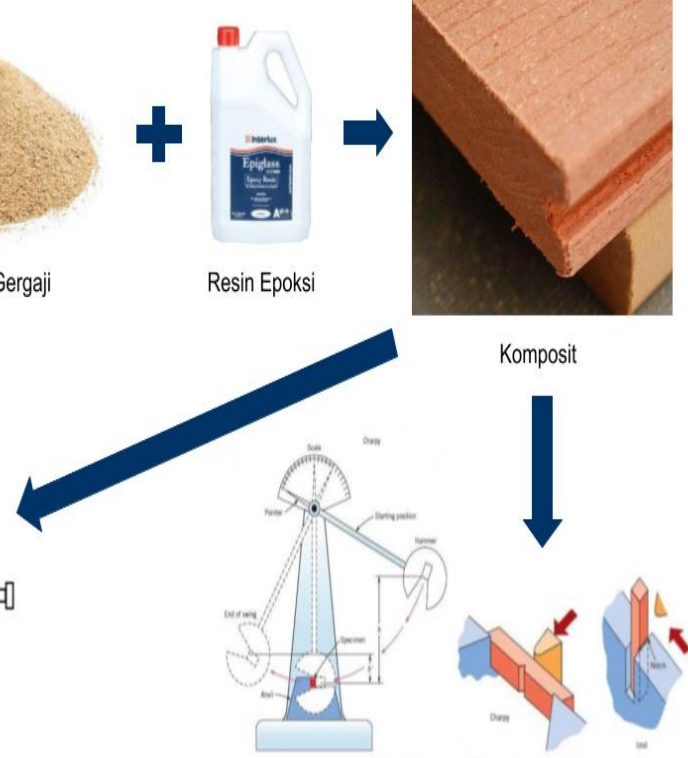

Uji Serap Bunyi

Gambar 1. Desain Penelitian

Gambar 1 menunjukkan desain penelitian tentang pembuatan komposit peredam bunyi berbasis serat daun lidah mertua dan serbuk gergaji. Serat daun lidah mertua yang direndam selama \pm 7 hari untuk memisahkan serat dari bagian daun lidah mertua. Kemudian, serat daun lidah mudah dicuci bersih untuk menghilangkan gel yang melekat di serat. Serat daun lidah mertua dikeringkan hingga kadar airnya berkurang dan siap digunakan. Serbuk gergaji yang digunakan harus dibersihkan agar tidak ada kotoran yang tertinggal. Kemudian, serat-serat dipotong kecil dan masing-masing komponen ditimbang dengan massa yang sudah ditentukan. Pembuatan matriks dilakukan dengan mencampurkan resin epoksi dengan hardener. Setelah itu, masing-masing penguat (serat daun lidah mertua dan serbuk gergaji) dicampurkan dengan matriks.

\subsection{Pembuatan Komposit}

Pembuatan komposit diawali dengan memotong kecil-kecil serat daun lidah mertua. Serat lidah mertua, serbuk gergaji, dan epoksi resin ditimbang sesuai variasi massa. Perbandingan konsentrasi fraksi volume dari serat daun lidah 
mertua, serbuk gergaji, dan epoksi resin yang digunakan sebesar 20\%:30\%:50\%, 25\%:25\%:50\%, dan 30\%:20\%:50\% yang ditandai sebagai sampel $\mathrm{A}, \mathrm{B}$, dan $\mathrm{C}$ dengan ketebalan $2 \mathrm{~cm}$ untuk uji serap bunyi. Perbandingan konsentrasi fraksi volume yang digunakan dalam sampel uji impak sama dengan uji serap bunyi, namun dengan ketebalan $0,5 \mathrm{~cm}$ dengan penamaan sampel G, H, dan I. Densitas ditentukan untuk mengetahui keterkaitan antara koefisien absorbsi bunyi dan nilai pecah. Pengambilan data untuk uji koefisien absorbsi bunyi dilakukan dengan cara mengukur taraf intensitas sebelum melewati medium penyerap $\left(\mathrm{TI}_{1}\right)$ dan setelah melewati medium penyerap $\left(\mathrm{TI}_{2}\right)$. Range frekuensi pada function generator diatur dari 250-3000 Hz. Uji pecah dilakukan mengayunkan beban pada alat uji untuk memukul komposit sampai pecah.

\subsection{Diagram Alir Penelitian}

Diagram alir penelitian yang telah dilakukan ditunjukkan oleh Gambar 2. Gambar 2 menunjukkan alur penelitian yang dilakukan dari mulai persiapan alat dan bahan hingga analisis hasil pengolahan data.

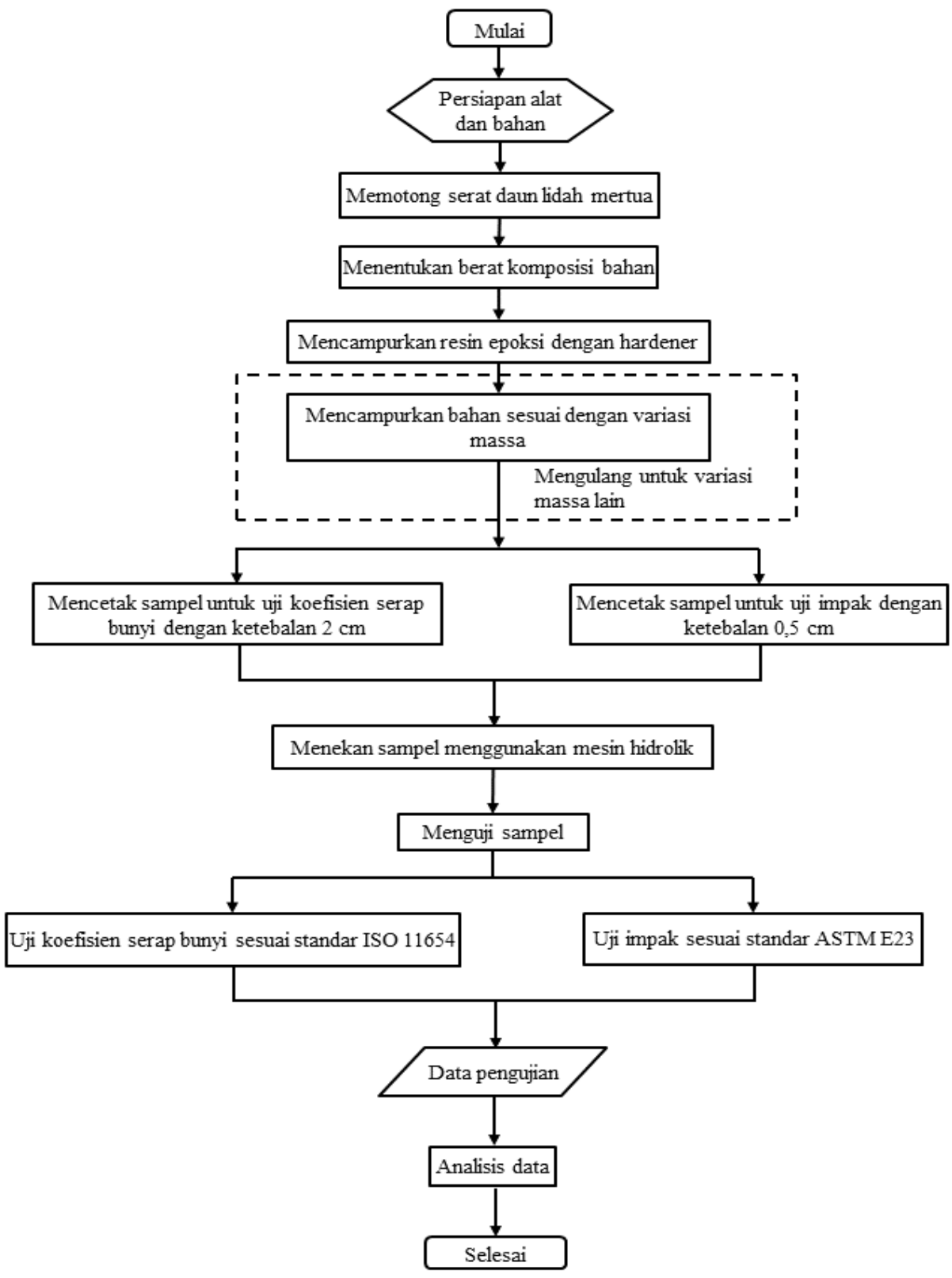

Gambar 2. Diagram Alir Penelitian 


\section{Hasil dan pembahasan}

Material komposit bahan dasar serat daun lidah mertua dengan serbuk gergaji berhasil dibuat, kemudian diuji sifat akustiknya. Pengujian terhadap komposit dilakukan untuk mengetahui nilai koefisien serap bunyi dari material komposit. Hubungan koefisien serap bunyi terhadap frekuensi seperti Gambar 3.

Hasil koefisien absorbsi bunyi rata-rata untuk komposit serat daun lidah mertua dengan serbuk gergaji pada sampel A, B, dan C sebesar 0,643; 0,711; dan 0,877 ditunjukkan pada Gambar 3. Hasil pengujian menunjukkan koefisien absorbsi bunyi meningkat dengan bertambahnya konsentrasi serat [7]. Komposisi konsentrasi tidak homogen menyebabkan sebaran filler dan matriks tidak merata sehingga berdampak pada koefisien absorbsi bunyi. Hal tersebut menyebabkan adanya celah pada sampel sehingga cenderung menghasilkan porositas besar atau kerapatan semakin kecil.Intensitas bunyi akan sebanding dengan nilai frekuensi dan akan berbanding terbalik dengan densitas material. Densitas material menentukan porositas yang dimiliki oleh material tersebut, semakin tinggi densitas maka porositasnya akan berkurang [8]. Kekuatan penyerap gelombang suara ditentukan oleh besarnya porositas yang dimiliki bahan akustik, semakin tinggi porositas yang dimiliki maka daya serap suaranya akan semakin tinggi [9].

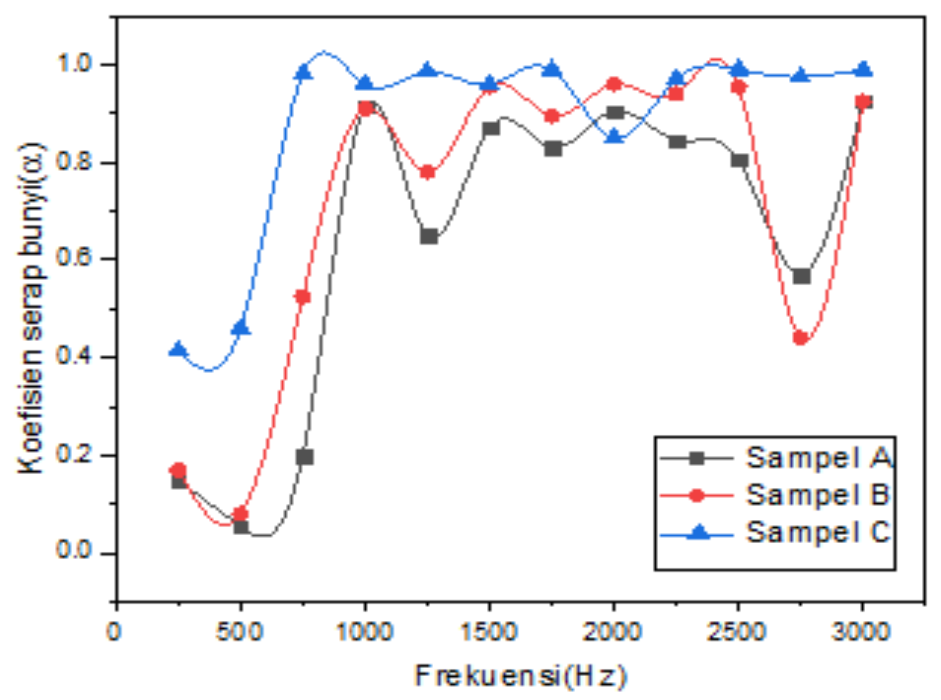

Gambar 3. Koefisien absorbsi bunyi komposit serat daun lidah mertua dengan serbuk gergaji pada frekuensi $250 \mathrm{~Hz}-$

$2000 \mathrm{~Hz}$

Koefisien serap bunyi merupakan nilai yang dimiliki oleh material dalam menyerap gelombang suara. Menurut ISO 11645, material akustik yang dikategorikan memiliki daya serap gelombang bunyi adalah material dengan koefisien serap bunyi lebih besar dari 0,15 [10]. Ketebalan material akan mempengaruhi koefisien serap bunyi, selain ketebalan faktor lain yang mempengaruhi adalah porositas dan densitas material [11]. Porositas akan menyebabkan gelombang suara terpantul dalam rongga-rongga material sehingga energinya akan semakin berkurang dan intensitasnya akan menurun [9].

Kandungan selulosa pada serat daun lidah mertua memiliki nilai $64 \%$ - 71\%, material yang mengandung selulosa mempunyai daya serap yang baik terhadap bunyi $[12,13]$. Karakteristik serat daun lidah mertua dan serbuk gergaji memiliki sifat fisik berpori yang menyebabkan nilai koefisien absorbsi bunyi tinggi. Porositas berhubungan dengan kerapatan yang ditunjukkan pada Gambar 4. 


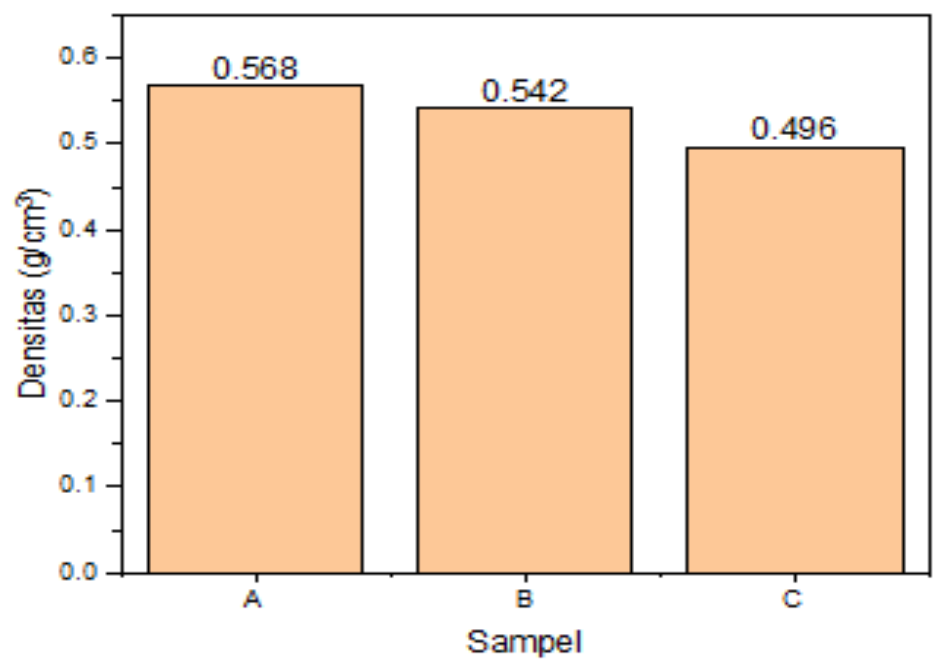

Gambar 4. Densitas komposit serat lidah mertua dengan serbuk gergaji

Kerapatan atau densitas komposit seperti Gambar 3. Hasil densitas komposit serat daun lidah mertua dengan serbuk gergaji pada sampel $\mathrm{A}, \mathrm{B}$, dan C sebesar 0,568 g/cm3; 0,542 g/cm3; dan 0,496 g/cm3. Densitas menyebabkan gelombang bunyi datang mengenai permukaan sampel mengalami pergeseran antara molekul serat. Gelombang bunyi akan merambat melalui pori-pori dalam komposit [14]. Semakin tinggi nilai densitas maka nilai koefisien absorbsi bunyi akan semakin rendah [8]. Penyerap bunyi harus memiliki kekuatan yang baik, oleh karena itu diperlukan pengujian kekuatan dari sampel. Pengujian kuat pecah bertujuan untuk mengetahui ketahanan sampel terhadap benturan pada Gambar 5.

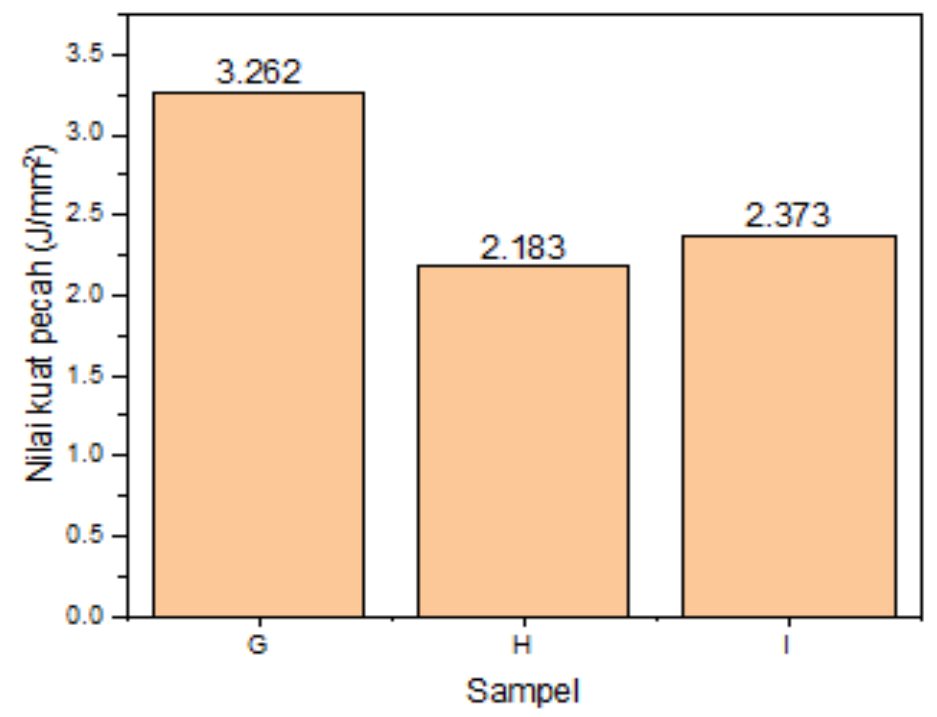

Gambar 5. Nilai kuat pecah komposit serat daun lidah mertua dengan serbuk gergaji

Gambar 5. menunjukkan kuat pecah komposit serat daun lidah mertua dengan serbuk gergaji pada sampel G, H, dan I sebesar 3,262 J/mm2; 2,183 J/mm2; dan 2,373 J/mm2. Kuat pecah komposit serat daun lidah mertua dengan serbuk gergaji memiliki sifat getas dan kerapatan tinggi ditunjukkan seperti Gambar 6. 


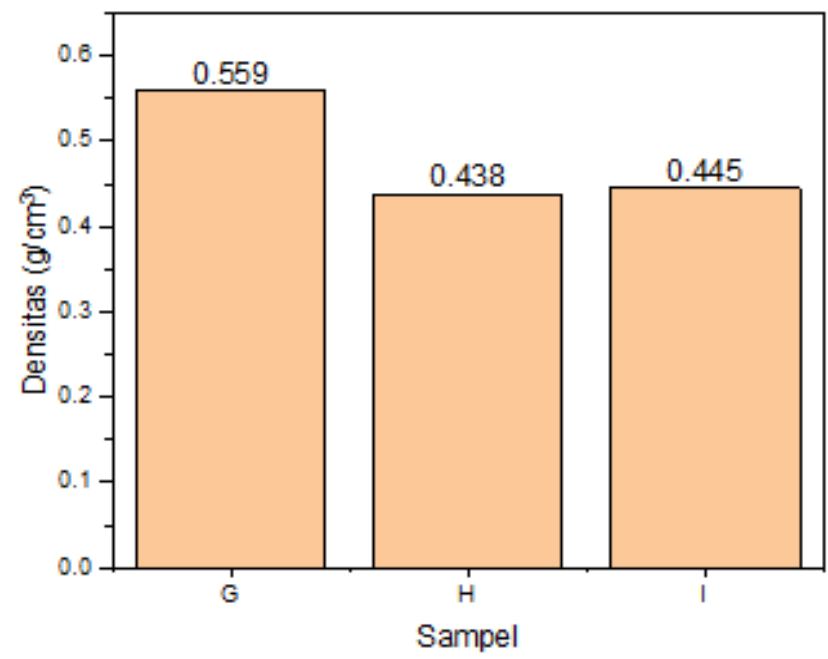

Gambar 6. Densitas kuat pecah komposit serat daun lidah mertua dengan serbuk gergaji

Analisis data penelitian menunjukkan bahwa nilai densitas tinggi menghasilkan kuat pecah yang tinggi seperti pada Gambar 5. Konsentrasi limbah kertas semakin tinggi menyebabkan kerapatan atau densitas pada sampel semakin tinggi, sehingga komposit tidak mudah mengalami keretakan. Penyebab kuat pecah rendah adalah void atau kekosongan celah pada ikatan setiap partikel yang mengakibatkan komposit lebih rapuh. Campuran konsentrasi komposisi tidak merata juga mengakibatkan void sehingga ikatan antara filler dan matriks lemah [15].

\section{Kesimpulan}

Berdasarkan hasil penelitian ini dapat disimpulkan bahwa; Konsentrasi serat daun lidah mertua tinggi dan serbuk gergaji rendah menghasilkan koefisien absorbsi bunyi yang tinggi, namun nilai kuat pecah semakin rendah, Semakin tinggi nilai densitas dapat menyebabkan nilai koefisien bunyi semakin rendah dan nilai kuat pecah semakin tinggi, Nilai koefisien absorbsi bunyi komposit serat daun lidah mertua dengan serbuk gergaji untuk masing-masing sampel adalah 0,$643 ; 0,711 ;$ dan 0,877 , Nilai kuat pecah komposit serat daun lidah mertua dengan serbuk gergaji untuk masing-masing sampel adalah $3,262 \mathrm{~J} / \mathrm{mm}^{2} ; 2,183 \mathrm{~J} / \mathrm{mm}^{2} ;$ dan $2,373 \mathrm{~J} / \mathrm{mm}^{2}$.

\section{Ucapan Terima Kasih}

Terima kasih kepada Kemendikbud Ristek/BRIN melalui Universitas Jenderal Soedirman atas pendanaan BLU Skim Riset Peningkatan Kompetensi Tahun 2021.

\section{Daftar Pustaka}

[1] Syaiful, S. \& Lutfi, A.,. Analisis Pengaruh Kecepatan Lalu Lintas Terhadap Kebisingan yang Ditimbulkan Kendaraan Bermotor. ASTONJADRO: Jurnal Rekayasa Sipil. 2020; IV(1): p. 13-19.

[2] Nisa, Utlatun. Pembuatan Komposit Material Peredam Akustik Berbahan Dasar Dari Serat Sabut Kelapa, Pelepah Pisang, Lidah Mertua Dan Epoxy Resin. Semarang: UIN Walisongo; 2018.

[3] Juhana, Riyadi. Biomaterial-Botani Implementasi untuk Material Pertahanan. Bogor: Universitas Pertahanan; 2020.

[4] Gibson, R. F. Principles Composite Material Mechanics. Boca Raton: CRC Press; 2016.

[5] Gonzalez, A.E. How Do Acoustic Materials Work?. London: IntechOpen; 2019.

[6] Callister, William D. Material Science and Engineering an Introduction. New York: John Wiley and Sons; 2019. 
[7] Kirana, Astrid. Efek Penambahan Serat Gelas pada Komposit Polyurethane terhadap Nilai Koefisien Absorbsi Suara dan Sifat Mekanik Komposit Door Panel. Surabaya: Institut Teknologi Sepuluh Nopember; 2016.

[8] Elvaswer, \& Ridhola, F. Pengukuran Koefisien Absorpsi Material Akustik Dari Serat Alam dan Ampas Tebu Sebagai Pengendali Kebisingan. Jurnal Ilmu Fisika. 2015; 7(1).

[9] Rus, A. Z., Azahari, M. M., Kormin, S., Soon, L. B., Zaliran, M. T., \& Sadrina, A. Hybrid Waste Filler Filled Bio-Polymer Foam Composites for Sound Absorbent Materials. AIP Publishing. 2017. doi:10.1063/1.4999883.

[10] Sound absorbers for use in buildings — Rating of sound absorption (ISO Standard No. ISO 11654: 1997). https://www.iso.org/standard/19583.html. Jenewa: International Organization for Standardization. Acoustics (ISO); 1997. (Diakses pada tanggal 10 Oktober 2021).

[11] Acoustic and Thermal Insulating Materials. Dalam Y. Li, \& R. Shuxia, Building Decorative Materials. Sawston: Woodhead Publishing; 2011.p. 359-374. doi:10.1533/9780857092588.359

[12] Kurniawan, Aji dan Nur Rahmawati. Inovasi Bahan Penyerap Bunyi dari Limbah Pabrik Poles Beras di Karangpandan Karanganyar. Prosiding (SIAR) Seminar Ilmiah Arsitektur 2020. 21 Januari 2020; Surakarta, Indonesia. Publikasi Ilmiah Universitas Muhammadiyah Surakarta; 2020. ISSN 2721-8686.

[13] Sari, K. P. \& Azizah, N. Pengaruh Komposisi Jenis Media Serbuk Gergaji, Limbah Kapuk dan Tongkol Jagung Pada Pertumbuhan Hasil Jamur Tiram Putih (Pleurotus Ostreatus). Jurnal Produksi Tanam; 2020. VIII(5): p. 495502.

[14] Sandi., dkk. Pengukuran Koefisien Serapan Bunyi Spons dan Styrofoam dengan Menggunakan Smartphone. Jurnal Riset Fisika Indonesia (JRFI); 2020. 1(1): p. 13-16.

[15] Hardiana, Fery. Perancangan Alat Uji Impak Metode Charpy dan Izod. Majalengka: Universitas Majalengka; 2021. 